\title{
PENGEMBANGAN MEDIA PREZI PADA PEMBELAJARAN MENULIS CERITA PENDEK SISWA KELAS XI SMA SE-KOTA TANGERANG DI ERA DIGITAL
}

\author{
Winda Dwi Hudhana*1, Hamdah Siti Hamsanah Fitriani ${ }^{2}$ \\ 1,2 Program Studi Pendidikan Bahasa dan Sastra Indonesia, \\ Universitas Muhammadiyah Tangerang \\ Jalan Perintis Kemerdekaan 1/33 Cikokol Kota Tangerang, Banten, Indonesia \\ Email:Windhana89@gmail.com ${ }^{* 1}$, vitrianivit@gmail.com ${ }^{2}$
}

\begin{abstract}
Abstrak
Penelitian ini bertujuan menjelaskan hasil pengembangan media Prezi pada pembelajaran menulis cerita pendek siswa kelas XI SMA se-Kota Tangerang di era digital. Metode dalam penelitian ini yaitu metode penelitian pengembangan pengembangan dengan langkah-langkah yaitu observasi lapangan, perencanaan dan rancangan penelitian, pengembangan produk, validasi produk, revisi produk, uji coba lapangan, revisi uji coba lapangan, dan implementasi media pembelajaran. Teknik pengumpulan data menggunakan tes dan angket. Instrumen penelitian yaitu melalui lembar angket dan tes. Teknik analisis data menggunakan teknik kecenderungan data. Uji validitas dilakukan kepada 5 ahli media Prezi dan 5 ahli materi cerita pendek. Hasil penelitian menunjukkan bahwa media Prezi layak dan efektif diimplementasikan pada pembelajaran cerita pendek siswa SMA kelas XI karena media Prezi mudah dibuat oleh guru, tampilan Prezi lebih menarik perhatian siswa, guru dapat mengkreasikan media pembelajaran sesuai dengan kreativitas guru dan mudah dipahami siswa. Berdasarkan hasil validasi lima ahli media Prezi rata-rata diperoleh $85,2 \%$ dikategorikan layak. Validasi lima ahli pembelajaran menulis cerita pendek memperoleh nilai rata-rata sebesar $86,8 \%$ dengan kategori layak. Hasil uji coba media Prezi pada pembelajaran menulis cerita pendek memperoleh nilai rata-rata sebesar 78,6 . Pemakaian produk media Prezi pada pembelajaran menulis cerita pendek memperoleh nilai rata-rata sebesar 78 dari 30 siswa. Implementasi produk media Prezi pada pembelajaran menulis cerita pendek memperoleh nilai rata-rata sebesar 73 dari 30 siswa. Implementasi produk media prezi pada pembelajaran menulis cerita pendek memperoleh nilai rata-rata sebesar 65,5 dari 20 siswa.
\end{abstract}

Kata kunci: media Prezi, pembelajaran menulis cerita pendek, era digital

\section{PREZI MEDIA DEVELOPMENT IN LEARNING TO WRITE SHORT STORIES FOR CLASS XI HIGH SCHOOL STUDENTS IN TANGERANG CITY IN THE DIGITAL ERA}

\begin{abstract}
This study aims to explain the results of Prezi's media development in learning to write short stories for XI grade high school students in Tangerang City in the digital era. The method in this research is a development research methodology with steps namely field observation, research planning and design, product development, product validation, product revision, field testing, revision of field trials, and implementation of learning media. Data collection techniques using


tests and questionnaires. The research instrument was through questionnaires and tests. Data analysis techniques using data trend techniques. The validity test was carried out on 5 Prezi media experts and 5 short story material experts. The results showed that the Prezi media was feasible and effective to be implemented in the learning of the XI grade high school students 'short stories because the Prezi media was easy to make by the teacher, Prezi's appearance attracted students' attention more, the teacher could create learning media according to the teacher's creativity and was easily understood by students. Based on the results of the validation of the five Prezi media experts, an average of $85.2 \%$ was categorized as feasible. The validation of five learning experts to write short stories obtained an average score of $86.8 \%$ with a decent category. The results of the Prezi media trial on learning to write short stories obtained an average score of 78.6. The use of Prezi media products in learning to write short stories obtained an average score of 78 out of 30 students. The implementation of Prezi media products in learning to write short stories obtained an average score of 73 out of 30 students. The implementation of Prezi media products in learning to write short stories obtained an average score of 65.5 from 20 students.

Keywords: Prezi media, learning to write short stories, digital era

\section{A. Pendahuluan}

Keterampilan menulis pada era digital sangat dibutuhkan agar penyebaran informasi dapat tepat sasaran, sehingga cakrawala pembaca semakin terbuka dan tajam. Seseorang yang menguasai keterampilan menulis dengan baik, maka ia juga menguasai keterampilan berbahasa yang lain (Karto dkk., 2019:2718). Keterampilan tersebut apabila dikuasai dengan baik, maka mampu membentuk kemampuan berpikir dan bernalar tingkat tinggi. Penulis yang memiliki memampuan menalar yang baik tentu tidak akan kesulitan dalam menyampaikan ide dan gagasan dalam bentuk tulisan (Helda, 2017:217). Keterampilan menulis cerita pendek merupakan bentuk pembelajaran sastra yang dapat diajarkan untuk mengasah kemampuan berpikir kreatif, inovatif, dan kritis dengan cara siswa dibimbing oleh guru melakukan kegiatan imajinasi dalam merangkaikan peristiwa satu ke peristiwa lain mulai dari pengenalan, konflik, klimaks, dan penyelesaian menjadi sebuah cerita dengan batasan permasalahan dan alur yang dituangkan dalam tulisan (Noermanzah, 2017:27-28).

Menulis cerita pendek bukanlah bakat, namun sebuah keterampilan yang harus terus dilatih. Keterampilan menulis cerita pendek dapat dikuasai dengan latihan yang teratur dan berkesinambungan (Irawan \& Sukmana, 2019:10). Melalui keterampilan menulis cerita pendek, peserta didik dapat berkomunikasi dengan lawan bicara tanpa harus bertatap muka. Selain itu, peserta didik dapat berkarya 
melalui tulisan yang berupa cerita pendek, novel, drama, puisi, dan lainnya (Saputro, 2017:195).

Berdasarkan observasi yang dilakukan di SMA se-Kota Tangerang didapatkan bahwa keterampilan menulis cerita pendek siswa kelas XI masih kesulitan dalam membuat cerita pendek. Kesulitan tersebut terkait dengan pemilihan tema dan ide cerita pendek, pengembangan cerita pendek, dan diksi dalam membuat cerita pendek. Salah satu faktor yang mempengaruhi hal tersebut yaitu pengguaan media pembelajaran yang kurang bervariasi dan kurang tepat sehingga siswa merasa bosan dan kurang tertarik dengan pembelajaran cerita pendek.

Peranan media pembelajaran sangat menentukan keberhasilan pembelajaran (Argarini \& Sulistyorini, 2018:211). Media pembelajaran digunakan sebagai jembatan perantara dalam pembelajaran sehingga pembelajaran terasa menyenangkan dan dapat membangkitkan antusias peserta didik (Noermanzah dkk., 2018:116). Pemilihan media pembelajaran Prezi dalam penelitian ini berdasarkan dengan pemanfaatan media komputer di era digital. Prezi merupakan aplikasi yang memadukan kreativitas seseorang dengan kecanggihan teknologi dalam merancang presentasi digital berbasis online (Argarini \& Sulistyorini, 2018:211). Aplikasi Prezi dan PowerPoint sama-sama dirancang untuk keperluan presentasi, namun aplikasi Prezi memiliki tampilan yang lebih menarik dan memiliki banyak keunggulan. Media pembelajaran Prezi juga dibuat dengan misi "membuat berbagi ide menjadi lebih menarik" maka Prezi dibuat menjadi alat untuk mengembangkan dan berbagi ide dalam bentuk visual naratif dengan tampilan yang atraktif (Suryani, Setiawan, \& Putria, 2018:79).

Prezi merupakan perangkat lunak yang digunakan untuk presentasi berbasis internet yang memiliki keunggulan karena menggunakan program Zooming User Interface (ZUI) yang memungkinkan pengguna memperbesar atau memperkecil tampilan (Dewi \& Latifah, 2016:48). Senada dengan pendapat tersebut Saputri dkk. (2015) mengemukakan bahwa keunggulan media pembelajaran Prezi adalah zoomable canvas, sehingga slide dapat fokus dalam setiap kalimat dengan 
pergerakan slide yang dinamis dan variatif. Selain itu, aplikasi Prezi berbasis adobe air sehingga video dan animasi yang ditampilan bisa dijalankan dengan ringan (Mahyuddin, Wati, \& Misbah, 2017:231). Pengguna aplikasi prezi dapat memberikan variasi-variasi video dan animasi yang beragam sehingga tampilan aplikasi Prezi lebih menarik dan tidak monoton.

Penelitian sebelumnya yang telah meneliti mengenai media pembelajaran prezi yaitu penelitian yang dilakukan Argarini \& Sulistyorini (2018). Hasil penelitian ini menunjukkan bahwa media pembelajaran Prezi mampu mendukung pembelajaran analisis vektor dengan memperhatikan prinsip visual. Media yang dikembangkan layak digunakan dalam pembelajaran analisis vektor bagi mahasiswa Pendidikan Matematika IKIP Budi Utomo Malang. Media yang layak ini memenuhi aspek kevalidan dan keefektifan. Selain itu, penelitian dilakukan oleh Saputri dkk., (2015), bahwa media Prezi layak digunakan sebagai alat bantu guru dalam pembelajaran akutansi. Terdapat perbedaan motivasi belajar siswa sebelum dan sesudah pembelajaran menggunakan media presentasi Prezi.

Dari beberapa penelitian relevan di atas, menunjukkan bahwa media Prezi belum dikembangkan dalam meningkatkan kemampuan menulis cerita pendek siswa. Untuk itu, penelitian ini bertujuan untuk menjelaskan hasil pengembangan media Prezi dan efektivitas media Prezi pada pembelajaran menulis cerita pendek siswa kelas XI SMA se-Kota Tangerang di era digital.

\section{B. Metode Penelitian}

Penelitian ini menggunakan metode penelitian pengembangan (research and development). Pada penelitian pengembangan menggunakan model Borg \& Gall (2005). Pada penelitian pengembangan, tahap pertama peneliti melakukan pengumpulan informasi awal yaitu dengan observasi pada beberapa sekolah mengenai permasalahan media pembelajaran terkait dengan keterampilan menulis cerita pendek di kelas XI SMA. Tahap kedua, peneliti menyimpulkan permasalahan berdasarkan obeservasi awal. Peneliti melakukan perencanaan dan perancangan penelitian. Peneliti menggunakan media pembelajaran Prezi dalam keterampilan menulis cerita pendek siswa kelas XI SMA. 
Tahap ketiga, peneliti mengembangkan format media Prezi berkaitan dengan keterampilan menulis cerita pendek siswa kelas XI SMA. Peneliti mengembangan media Prezi agar memudahkan guru dalam menyampaikan materi keterampilan menulis cerita pendek. Tahap keempat, peneliti melakukan validasi produk kepada dua ahli yang terkait dengan media pembelajaran Prezi dan keterampilan menulis cerita pendek siswa kelas XI SMA. Peneliti melibatkan lima ahli media pembelajaran prezi dan keterampilan menulis cerita pendek siswa kelas XI SMA yaitu guru dan dosen. Validasi dan evaluasi oleh ahli dilakukan untuk mengetahui kekurangan atau kesalahan dalam produk.

Tahap kelima, peneliti melakukan revisi produk media pembelajaran Prezi yang terkait dengan kekurangan ataupun terdapat kesalahan dalam produk. Tahap keenam, peneliti melakukan uji lapangan media pembelajaran Prezi dalam keterampilan menulis cerita pendek terhadap 10 siswa kelas XI SMA. Tahap ketujuh, peneliti melakukan revisi yang berkaitan dengan uji lapangan penggunaan media Prezi pada pembelajaran menulis cerita pendek yang telah diuji coba pada siswa kelas XI SMA. Peneliti melakukan evaluasi media Prezi pada pembelajaran menulis cerita pendek. Tahap kedelapan, peneliti melakukan implementasi media pembelajaran Prezi pada pembelajaran menulis cerita pendek siswa kelas XI SMA. Implementasi dilakukan pada tiga sekolah yang telah dipilih secara simple random sampling.

Populasi pada penelitian ini siswa kelas XI SMA se-Kota Tangerang. Sampel dalam penelitian ini yaitu siswa kelas XI SMA Negeri 11 Kota Tangerang, SMA Muhammadiyah 3 Kota Tangerang, dan SMA PGRI 109 Kota Tangerang yang terletak di Kota Tangerang Provinsi Banten. Data dalam penelitian ini yaitu hasil test siswa kelas XI SMA Negeri 11 Kota Tangerang, SMA Muhammadiyah 3 Kota Tangerang, dan SMA PGRI 109 Kota Tangerang berkaitan dengan keterampilan menulis cerita pendek menggunakan media Prezi. Sumber data dalam penelitian ini yaitu sepuluh validator ahli media Prezi dan ahli pembelajaran menulis cerpen, serta siswa kelas XI SMA Negeri 11 Kota Tangerang, SMA Muhammadiyah 3 Kota Tangerang, dan SMA PGRI 109 Kota Tangerang. 
Instrumen dalam penelitian ini yaitu dibedakan menjadi dua yaitu melalui lembar angket dan tes. Lembar angket berisi mengenai penilaian validasi evaluasi media Prezi dan keterampilan menulis cerita pendek. Lembar tes berupa essay yang terkait dengan soal yang menguji penguasaan keterampilan menulis cerita pendek pada siswa kelas XI SMA Negeri 11 Kota Tangerang, SMA Muhammadiyah 3 Kota Tangerang, dan SMA PGRI 109 Kota Tangerang. Validasi instrumen dilakukan oleh guru dan dosen ahli media Prezi dan keterampilan menulis cerita pendek, validasi instrumen berisi mengenai aspek materi keterampilan menulis cerita pendek, dan tampilan media Prezi.

Kriteria validasi produk media Prezi menggambarkan efektivitas dan kelayakan produk media Prezi digunakan dalam pembelajaran keterampilan menulis cerita pendek. Kriteria validasi produk menggunakan rumus sebagai berikut,

$$
\begin{aligned}
& P=\frac{X}{X i} 100 \% \\
& \text { Ket: } \quad \mathrm{P}=\text { Presentase } \\
& X=\text { Jumlah keseluruhan jawaban responden } \\
& \mathrm{Xi}=\text { Jumlah keseluruhan nilai ideal }
\end{aligned}
$$

Kriteria kelayakan produk ditetapkan berdasarkan kriteria berikut.

Tabel 1. Kriteria Kelayakan Produk

\begin{tabular}{cccll}
\hline No. & Kategori & \multicolumn{1}{c}{ Presentase } & \multicolumn{1}{c}{ Kualifikasi } & \multicolumn{1}{c}{ Ekuivalen } \\
\hline 1. & A (5) & $81 \%-100 \%$ & Sangat valid & Sangat layak \\
\hline 2. & B (4) & $61 \%-80 \%$ & Valid & Layak \\
\hline 3. & C (3) & $41 \%-60 \%$ & Cukup Valid & Cukup Layak \\
\hline 4. & D (2) & $21 \%-40 \%$ & Kurang Valid & Kurang Layak \\
\hline 5. & E (1) & $0 \%-20 \%$ & Tidak Valid & Tidak Layak \\
\hline
\end{tabular}

Teknik analisis data menggunakan teknik kecenderungan data. Penilaian produk dilakukan sesuai dengan tanggapan kualitas produk media pembelajaran Prezi. Selain itu, analisis data tes essay dilakukan pada hasil tes menulis cerita pendek siswa kelas XI SMA. Data tes hasil menulis cerita pendek dianalisis untuk mengetahui efektivitas penggunaan media pembelajaran Prezi yang menggenakan rumus rata-rata nilai berikut. 
$\bar{x}=\frac{\Sigma x}{n}$

Keterangan:

$\bar{x}=$ Rata-rata nilai

$\Sigma x=$ Hasil skor yang diperoleh siswa

$n$ = Jumlah siswa

\section{Hasil Penelitian dan Pembahasan}

\section{Hasil Penelitian}

Hasil validasi lima ahli media pembelajaran Prezi yaitu responden 1 diperoleh $82 \%$, responden 2 diperoleh $88 \%$, responden 3 diperoleh $82 \%$, responden 4 diperoleh $84 \%$, dan responden 5 diperoleh $90 \%$. Rata-rata validasi ahli media Prezi yaitu $85,2 \%$ dikategorikan layak. Validasi lima ahli keterampilan menulis cerita pendek yaitu responden 1 diperoleh $86 \%$, responden 2 diperoleh $90 \%$, responden 3 diperoleh $82 \%$, responden 4 diperoleh $92 \%$, dan responden 5 diperoleh $84 \%$. Rata-rata hasil validasi ahli keterampilan menulis cerita pendek yaitu $86,8 \%$ dikategorikan layak. Berikut ini hasil validasi digambarkan pada tabel berikut.

Tabel 2. Rekapitulasi Validasi Produk

\begin{tabular}{|c|c|c|c|}
\hline No. & Reponden & Hasil Validasi & Kriteria \\
\hline \multicolumn{4}{|c|}{ Validasi Ahli Media Pembelajaran Prezi } \\
\hline 1. & Responden 1 & $82 \%$ & Layak \\
\hline 2. & Responden 2 & $88 \%$ & Layak \\
\hline 3. & Responden 3 & $82 \%$ & Layak \\
\hline 4. & Responden 4 & $84 \%$ & Layak \\
\hline \multirow[t]{3}{*}{5.} & Responden 5 & $90 \%$ & Layak \\
\hline & Jumlah & $426 \%$ & \\
\hline & Rata-Rata & $85,2 \%$ & Layak \\
\hline \multicolumn{4}{|c|}{ Validasi Ahli Pembelajaran Keterampilan Menulis Cerita Pendek } \\
\hline 1. & Responden 1 & $86 \%$ & Layak \\
\hline 2. & Responden 2 & $90 \%$ & Layak \\
\hline 3. & Responden 3 & $82 \%$ & Layak \\
\hline 4. & Responden 4 & $92 \%$ & Layak \\
\hline \multirow[t]{3}{*}{5.} & Responden 5 & $84 \%$ & Layak \\
\hline & Jumlah & $434 \%$ & \\
\hline & Rata-Rata & $86,8 \%$ & Layak \\
\hline
\end{tabular}

Silampari Bisa: Jurnal Penelitian Pendidikan Bahasa Indonesia, Daerah, dan Asing Vol. 3, No. 2, 2020 
Hasil rekapitulasi validasi produk media Prezi yang digunakan pada pembelajaran menulis cerpen dapat lebih jelas dilihat dalam bentuk grafik sebagai berikut.

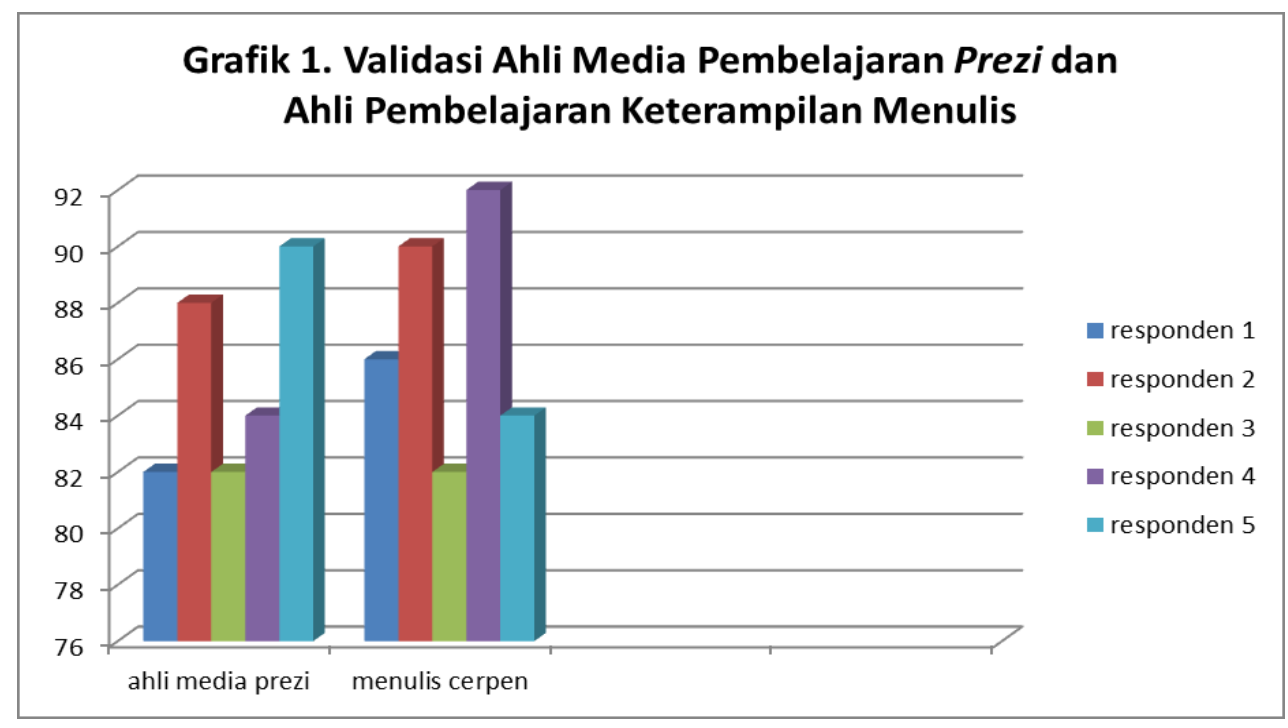

Penggunakan media Prezi pada pembelajaran menulis cerita pendek siswa kelas XI SMA memperoleh nilai rata-rata 78,6 dengan jumlah nilai 786 . Sesuai dengan KKM yang terdapat di SMA kota Tangerang yaitu 75. Berikut ini tabel hasil uji lapangan.

Tabel 3. Hasil Uji Coba Siswa Kelas XI

\begin{tabular}{clc}
\hline No. & \multicolumn{1}{c}{ Responden } & $\begin{array}{c}\text { Perolehan Nilai Keterampilan } \\
\text { Menulis Cerita Pendek }\end{array}$ \\
\hline 1. & Responden 1 & 80 \\
\hline 2. & Responden 2 & 77 \\
\hline 3. & Responden 3 & 76 \\
\hline 4. & Responden 4 & 82 \\
\hline 5. & Responden 5 & 86 \\
\hline 6. & Responden 6 & 70 \\
\hline 7. & Responden 7 & 75 \\
\hline 8. & Responden 8 & 78 \\
\hline 9. & Responden 9 & 80 \\
\hline 10. & Responden 10 & 82 \\
\hline & Jumlah & 786 \\
\hline & Rata-rata Nilai & 78,6 \\
\hline
\end{tabular}

Hasil implementasi produk media Prezi pada pembelajaran menulis cerita pendek di SMAN 11 Kota Tangerang bahwa perolehan nilai terendah yaitu 60 sedangkan nilai tertinggi yaitu 85 . Perolehan nilai rata-rata sebesar 78 dari 30 
siswa. Hasil implementasi produk media Prezi pada pembelajaran menulis cerita pendek di SMAN 11 Kota Tangerang digambarkan dalam tabel berikut.

Tabel 4. Hasil Belajar Keterampilan Menulis Materi Cerita Pendek Siswa

Kelas XI SMA Negeri 11 Kota Tangerang

\begin{tabular}{ccc}
\hline No. & \multicolumn{1}{c}{ Nilai } & Pemerolehan Hasil Belajar \\
\hline 1. & Nilai Terendah & 60 \\
\hline 2. & Nilai Tertinggi & 85 \\
\hline & Jumlah & 2219 \\
\hline & Rata-rata & 78 \\
\hline
\end{tabular}

Hasil implementasi produk media Prezi pada pembelajaran menulis cerita pendek di SMAN PGRI 109 Kota Tangerang bahwa perolehan nilai terendah yaitu 50 sedangkan nilai tertinggi yaitu 82 . Perolehan nilai rata-rata sebesar 73 dari 30 siswa. Hasil implementasi produk media Prezi pada pembelajaran menulis cerita pendek di SMAN 109 Kota Tangerang digambarkan dalam tabel berikut.

Tabel 5. Perbandingan Hasil Belajar Keterampilan Menulis Materi Cerita Pendek Siswa

Kelas XI SMA PGRI 109 KotaTangerang

\begin{tabular}{ccc}
\hline No. & Nilai & Pemerolehan Hasil Belajar \\
\hline 1. & Nilai Terendah & 50 \\
\hline 2. & Nilai Tertinggi & 82 \\
\hline & Jumlah & 2192 \\
\hline & Rata-rata & 73 \\
\hline
\end{tabular}

Hasil implementasi produk media Prezi pada pembelajaran menulis cerita pendek di SMA Muhammadiyah 3 Kota Tangerang bahwa perolehan nilai terendah yaitu 50 sedangkan nilai tertinggi yaitu 82. Perolehan nilai rata-rata yaitu 65,5 dari 20 siswa. Hasil implementasi produk media Prezi pada pembelajaran menulis cerita pendek di SMAN Muhammadiyah 3 Kota Tangerang digambarkan dalam tabel berikut.

Tabel 6. Perbandingan Hasil Belajar Keterampilan Menulis Materi Cerita Pendek Siswa

Kelas XI SMA Muhammadiyah 3 KotaTangerang

\begin{tabular}{ccc}
\hline No. & Nilai & Pemerolehan Hasil Belajar \\
\hline 1 & Nilai Terendah & 56 \\
\hline 2 & Nilai Tertinggi & 78 \\
\hline & Jumlah & 1311 \\
\hline & Rata-rata & 65,5 \\
\hline
\end{tabular}

Silampari Bisa: Jurnal Penelitian Pendidikan Bahasa Indonesia, Daerah, dan Asing Vol. 3, No. 2, 2020 
Berdasarkan hasil validasi ahli media pembelajaran Prezi dan ahli materi pembelajaran cerita pendek menunjukkan bahwa media pembelajaran Prezi layak digunakan dalam pembelajaran cerita pendek. Implementasi produk pada siswa kelas XI SMA 11 Kota Tangerang, SMA PGRI 109 Kota Tangerang dan SMA Muhammadiyah 3 Kota Tangerang menunjukkan bahwa media pembelajaran Prezi dapat meningkatkan kemampuan menulis cerita pendek siswa. Media pembelajaran Prezi pada pembelajaran menulis cerita pendek dikembangkan dengan tujuan sebagai media pembelajaran yang dapat memotivasi siswa agar dapat menghasilkan cerita pendek yang imajinatif dan kreatif.

\section{Pembahasan}

Produk media pembelajaran Prezi pada penelitian ini menunjukkan hasil efektif dan layak dalam meningkatkan keterampilan menulis cerita pendek siswa kelas XI SM di Tangerang. Hal tersebut sesuai dengan penelitian sebelumnya yang dilakukan Argarini \& Sulistyorini (2018). Namun, perbedaannya terkait pada bidang keilmuan yang digunakan pada studi Matematika. Hasil penelitian yang dilakukan oleh Argarini \& Sulistyorini (2018) yaitu media pembelajaran Prezi dalam pembelajaran analisis vektor dengan memperhatikan prinsip visual. Media Prezi yang digunakan memenuhi aspek kevalidan dan keefektifan. Selain itu, penelitian terdahulu yang dilakukan oleh Nasution \& Siregar (2019) menunjukkan keefektifan media pembelajaran Prezi dalam mata pelajaran Matematika yang memenuhi syarat keefektifan dan kepraktisan dalam pembelajaran geometri.

Keberhasilan pengembangan media Prezi dalam meningkatkan keterampilan menulis cerpen siswa karena melalui tahapan penelitian pengembangan dengan model Borg \& Gall (2005). Tahapan tersebut yaitu, tahap observasi sebagai tahap pertama penelitian yaitu dengan mengumpulkan informasi awal. Pada tahap ini, peneliti memilih secara random sekolah yang akan digunakan penelitian yaitu SMAN 11 Kota Tangerang, SMA PGRI 109 Kota Tangerang, dan SMA Muhammadiyah 3 Kota Tangerang. Peneliti menyimpulkan beberapa hal berdasarkan hasil observasi yaitu: 1) siswa kelas XI di SMA tersebut kesulitan dalam menulis cerita pendek baik berupa ide, diksi, penggambaran alur, dan 
sebagainya, 2) guru kurang selektif dalam memilih media pembelajaran yang tepat dalam pembelajaran menulis cerita pendek, 3) guru belum melakukan inovasi dalam menghadirkan media pembelajaran keterampilan menulis cerita pendek, dan 4) siswa kurang bersemangat dan kurang termotivasi dalam menulis cerita pendek, karena mereka beranggapan bahwa menulis merupakan keterampilan yang sulit.

Tahap kedua, peneliti melakukan penyimpulan permasalahan yaitu keterampilan menulis cerita pendek siswa kelas XI yang masih rendah dan guru yang masih kesulitan pengadaan maupun pemilihan media pembelajaran yang efektif. Penyimpulan masalah ini berdasarkan hasil observasi pada siswa kelas XI di SMAN 11 Kota Tangerang, SMA PGRI 109 Kota Tangerang, dan SMA Muhammadiyah 3 Kota Tangerang. Peneliti menerapkan media pembelajaran Prezi sebagai media pembelajaran keterampilan menulis cerita pendek.

Tahap ketiga, peneliti melakukan pengembangan media Prezi pada pembelajaran menulis cerita pendek siswa kelas XI. Peneliti membuat media pembelajaran Prezi dengan materi cerita pendek. Selanjutnya, peneliti membuat alat evaluasi untuk validasi ahli media pembelajaran Prezi dan ahli materi pembelajaran keterampilan menulis cerita pendek. Alat evaluasi yang digunakan peneliti untuk mengetahui hasil belajar dan efektivitas media Prezi pada pembelajaran menulis cerita pendek siswa kelas XI.

Alat evaluasi yang digunakan dibedakan menjadi dua yaitu validasi media pembelajaran Prezi dan materi pembelajaran keterampilan menulis cerita pendek. Pengembangan alat validasi media pembelajaran Prezi mencakup aspek tampilan slide, aspek gambar animasi, aspek simbol dan tulisan, aspek penggunaan bahasa, dan aspek efektivitas media Prezi. Sedangkan pengembangan keterampilan menulis mencakup aspek materi cerita pendek, aspek minat pada materi, aspek pemahaman terhadap materi, aspek cakupan kurikulum 2013 pada materi, aspek bahasa pada materi, aspek evaluasi, dan aspek motivasi pemahaman materi. 
Tahap keempat yaitu validasi produk media pembelajaran Prezi dalam keterampilan menulis cerita pendek siswa kelas XI SMA. Terdapat lima ahli media pembelajaran Prezi dan lima ahli keterampilan menulis cerita pendek siswa kelas XI SMA yang terdiri atas guru dan dosen. Perolehan hasil validasi dari ahli keterampilan menulis cerita pendek dan ahli media pembelajaran Prezi yaitu $86 \%$ dikategorikan layak.

Pada tahap kelima, peneliti merevisi produk media pembelajaran Prezi terkait dengan kekurangan yang terdapat pada media pembelajaran Prezi. Saran dari validator digunakan oleh peneliti untuk memperbaiki kekurangan produk. Tahap keenam, peneliti melakukan uji lapangan. Pengujian lapangan dilakukan pada 10 siswa dari SMAN 11 Kota Tangerang, SMA PGRI 109 Kota Tangerang dan SMA Muhammadiyah 3 Kota Tangerang. Hasil uji lapangan memberikan hasil rata-rata nilai perolehan hasil menulis cerita pendek yaitu 78,6. Oleh karena itu, dapat disimpulkan bahwa media pembelajaran Prezi layak digunakan dalam pembelajaran keterampilan menulis cerita pendek.

Pada tahap ketujuh, setelah melakukan uji lapangan, peneliti melakukan revisi. Peneliti memperbaiki kekurangan dan kesalahan pada produk media Prezi pada pembelajaran menulis cerita pendek yang diuji coba kepada siswa kelas XI SMA. Hasil revisi produk media pembelajaran Prezi yang sudah dilakukan perbaikan akan diterapkan dalam penelitian. Tahap kedelapan yaitu implementasi produk media Prezi pada pembelajaran menulis cerita pendek. Peneliti melakukan penelitian pada tiga sekolah yaitu SMAN 11 Kota Tangerang, SMA PGRI 109 Kota Tangerang dan SMA Muhammadiyah 3 Kota Tangerang.

Hasil implementasi produk media Prezi pada pembelajaran menulis cerita pendek di SMAN 11 Kota Tangerang diperoleh nilai rata-rata sebesar 78. Penggunaan produk media Prezi pada pembelajaran menulis cerita pendek di SMAN PGRI 109 Kota Tangerang diperoleh nilai rata-rata sebesar 73. Sedangkan di SMA Muhammadiyah 3 Kota Tangerang, penggunaan media Prezi pada pembelajaran menulis cerita pendek diperolehan nilai rata-rata sebesar 65,5. Berdasarkan hasil implementasi tersebut, menunjukkan bahwa media 
pembelajaran Prezi layak dan efektif digunakan dalam pembelajaran menulis cerita pendek.

Berdasarkan hasil validasi ahli, uji lapangan, dan implementasi produk, media pembelajaran Prezi dinilai sangat efektif untuk mengajarkan keterampilan menulis cerita pendek. Secara umum, media pembelajaran Prezi layak digunakan dan efektif dalam pembelajaran menulis cerita pendek. Efektivitas media Prezi pada pembelajaran menulis cerita pendek meliputi:

1. Guru dapat membuat media Prezi dengan mengkreasikan materi dalam tampilan yang lebih modern.

2. Guru dapat menghemat waktu karena media pembelajaran Prezi mudah dalam pembuatan.

3. Guru dapat dengan mudah digunakan dengan tampilan yang menarik.

4. Guru dapat memasukan audio atau efek suara yang disesuaikan dengan materi.

5. Media pembelajaran Prezi dapat dibuat sesuai dengan materi dan kebutuhan pembelajaran.

6. Tampilan media pembelajaran Prezi sangat menarik, karena guru dapat memberikan tambahan animasi sesuai dengan materi.

\section{Simpulan}

Hasil penelitian menunjukkan bahwa media Prezi layak dan efektif diimplementasikan pada pembelajaran cerita pendek siswa SMA kelas XI karena media Prezi mudah dibuat oleh guru, tampilan Prezi lebih menarik perhatian siswa, guru dapat mengkreasikan media pembelajaran sesuai dengan kreativitas guru dan mudah dipahami siswa. Kemudian, layak dan efektifnya media Prezi dibuktikan dengan implementasi media Prezi pada pembelajaran menulis cerita pendek di SMAN 11 Kota Tangerang memperoleh nilai rata-rata sebesar 78 dari 30 siswa. Implementasi produk media Prezi pada pembelajaran menulis cerita pendek di SMAN PGRI 109 Kota Tangerang memperoleh nilai rata-rata sebesar 73 dari 30 siswa. Kemudian, implementasi produk media Prezi pada pembelajaran 
menulis cerita pendek di SMA Muhammadiyah 3 Kota Tangerang memperoleh nilai rata-rata sebesar 65,5 dari 20 siswa. Oleh karena itu, saran dalam penggunaan media pembelajaran Prezi dapat digunakan sebagai alat bantu mengajar guru yang efektif dalam pembelajaran keterampilan menulis cerita pendek di Sekolah. Media pembelajaran Prezi juga dapat digunakan dalam pembelajaran keterampilan yang lainnya karena media pembelajaran Prezi sangat menarik dan memudahkan siswa dalam memahami materi pembelajaran keterampilan berbahasa. Saran bagi peneliti selanjutnya yaitu terkait dengan penelitian media pembelajaran Prezi dalam materi pembelajaran keterampilan berbahasa agar pembelajaran keterampilan berbahasa lebih menarik dan mudah dipahami siswa.

\section{Daftar Pustaka}

Argarini, D. F., \& Sulistyorini, Y. (2018). Pengembangan Media Pembelajaran Berbasis Prezi Pada Matakuliah Analisis Vektor. Kalamatika Jurnal Pendidikan Matematika, 3(2), 209-222. doi:10.22236/kalamatika.vol3no2.2018pp209-222

Borg, W R \& Gall, M D. (2005). Educational Research: An Introduction, Fourth Edition. New York: Longman. Inc.

Dewi, K. P., \& Latifah, L. (2016). Efektivitas Metode Problem Posing Berbantu Media Prezi untuk Meningkatkan Hasil Belajar Siswa Materi Jurnal Penyesuaian. Economic Education Analysis Journal, 5(1), 44-57. https://journal.unnes.ac.id/sju/index.php/eeaj/article/view/9985

Helda, T. (2017). Menulis Teks Cerita Pendek Berbantuan Media Gambar Berseri Siswa Kelas VII SMP Islam Khaira Ummah Padang. Gramatika STKIP PGRI Sumatera Barat, 3(2). 217, doi:10.22202/jg.2017.v3i2.2186

Irawan, D., \& Sukmana, E. (2019). Menulis Cerita Pendek dengan Metode Outdoor Learning. Gondang: Jurnal Seni dan Budaya, 3(1), 10, https://doi.org/10.24114/gondang.v3i1.12498

Karto, Suhartono, Susetyo, Noermanzah, Maisarah, I. (2019). The Differences Ability in Writing Descriptive Texts by Using Chain Writing and Conventional Methods. International Journal of Scientific \& Technology Research, 8(10), 2718. 
Mahyuddin, R. S., Wati, M., \& Misbah, M. (2017). Pengembangan Media Pembelajaran Fisika Berbasis Zoomable Presentation Berbantuan Software Prezi pada Pokok Bahasan Listrik Dinamis. Berkala Ilmiah Pendidikan Fisika, 5(2), 231. doi:10.20527/bipf.v5i2.3588

Nasution, E. Y. P., \& Siregar, N. F. (2019). Pengembangan Media Pembelajaran Berbasis Prezi. Tarbawi: Jurnal IImu Pendidikan, 15(2), https://ejournal.iainkerinci.ac.id/index.php/tarbawi/article/view/466

Noermanzah, N. (2017). Plot in a Collection of Short Stories "Sakinah Bersamamu" Works of Asma Nadia with Feminimism Analysis. Humanus, 16(1), 27-28. doi:10.24036/jh.v16i1.7015

Noermanzah, N., Abid, S., \& Septaria, S. (2018). Improving the Ability of Writing a Narrative Charge by Using Animated Images Media Student Class V.B SD Negeri 17 Lubuklinggau. BAHTERA : Jurnal Pendidikan Bahasa dan Sastra, 17(2), 116. doi:10.21009/bahtera.172.9

Saputri, I. J., Irafahmi, D. T., \& Sumadi, S. (2016). Media Presentasi Prezi pada Mata Pelajaran Akuntansi untuk Meningkatkan Motivasi Belajar Siswa. Journal of Accounting and Business Education, 2(4). doi:10.26675/jabe.v2i4.6075

Saputro, A. N. (2017). Pengembangan Buku Ajar Menulis Cerita Pendek yang Berorientasi pada Karakter Cinta Tanah Air. Indonesian Language Education and Literature, 2(2), 195. doi:10.24235/ileal.v2i2.1199

Suryani, N., Setiawan, A., \& Aditin, P. (2018). Media Pembelajaran Inovatif dan Pengembangannya. Bandung: PT Remaja Rosdakarya. 